\title{
Thrombolysis Versus Anticoagulation for the Initial Treatment of Moderate Pulmonary Embolism: A Meta-Analysis of Randomized Controlled Trials
}

\author{
Hong Chen MD, Cheng Ren MD, and Hong Chen MD PhD
}

\begin{abstract}
BACKGROUND: Randomized trials and meta-analyses have reached conflicting conclusions regarding the risk benefit ratio of thrombolytic therapy or anticoagulant therapy in patients with moderate pulmonary embolism. To investigate the effect of initial thrombolysis and anticoagulant therapy in patients with moderate pulmonary embolism, we performed an updated meta-analysis. METHODS: We searched the MEDLINE, Embase, Cochrane Library, Wanfang, and CNKI databases for randomized controlled trials focusing on moderate pulmonary embolism. We then performed a meta-analysis of all randomized trials comparing thrombolytic therapy with heparin treatment in subjects with moderate pulmonary embolism. RESULTS: Fifteen trials involving 1,247 subjects were included. Compared with anticoagulation, thrombolytic therapy was associated with a significant reduction in recurrent pulmonary embolism or death $(1.94 \%$ vs $5.87 \%$, odds ratio $(\mathrm{OR})$ of $0.37,95 \%$ CI $0.21-0.66, P$ for heterogeneity $=.49)$, a nonsignificant increase in major bleeding $(3.57 \%$ vs $2.67 \%$, OR $1.34,95 \%$ CI 0.70-2.58), and a significant increase in non-major bleeding $(12.78 \%$ vs $3.65 \%$, OR $4.12,95 \%$ CI 2.37-7.17). Thrombolysis was associated with a significant reduction in recurrent pulmonary embolism or death in trials that enrolled both foreign subjects $(3.46 \%$ vs $7.76 \%$, OR $0.45,95 \%$ CI $0.23-0.86)$ and Chinese subjects (0\% vs $3.72 \%$, OR $0.18,95 \%$ CI $0.05-0.73)$. With regard to moderate pulmonary embolism, comparison of thrombolysis and anticoagulation showed a nonsignificant heterogeneity between the 2 trial groups $(P=.12)$. CONCLUSIONS: Both mortality and pulmonary embolism recurrence are decreased with thrombolysis compared with heparin treatment in patients with moderate pulmonary embolism. The risk of non-major bleeding is increased, but the risk of major bleeding is not. Keywords: pulmonary embolism; thrombolysis; heparin; meta-analysis. [Respir Care 2014;59(12):1880-1887. (C) 2014 Daedalus Enterprises]
\end{abstract}

\section{Introduction}

Pulmonary embolism is a life-threatening disease, with an estimated incidence of $6-7 / 10,000$ people, and it is

The authors are affiliated with the Department of Respiratory Medicine, The First Affiliated Hospital of Chongqing Medical University, Chongqing, China. Hong Chen MD is also affiliated with the Department of Respiratory Medicine, The People's Hospital of Yubei, District of Chongqing City, Chongqing, China.

This study was supported by the China Key Research Projects of the 12th National Five-Year Development Plan (2011BAI11BOO). The authors have disclosed no conflicts of interest.

Correspondence: Hong Chen MD PhD, Department of Respiratory Medicine, First Affiliated Hospital of Chongqing Medical University, No. 1, Yixue Road, Yuzhong District, Chongqing 400016, China. E-mail: hopehong2003@126.com.

DOI: $10.4187 /$ respcare.03197 associated with a 3-month mortality rate of up to $17 \% .^{1,2}$ To date, the use of thrombolysis is recommend only in patients with massive pulmonary embolism. Moderate pulmonary embolism is a defined subgroup of pulmonary embolism, in which patients have hemodynamic stability but with right ventricular enlargement or hypokinesia or elevation of biomarkers of right ventricular injury. The initial treatment of moderate pulmonary embolism with thrombolytic therapy or anticoagulation has been under dispute for $>3$ decades. The principal contradiction comes from different risk benefit ratios of treatment with thrombolytic therapy or anticoagulant therapy in randomized controlled trials (RCTs). The interpretation of metaanalyses $^{3-6}$ showed that thrombolytic therapy in patients with moderate pulmonary embolism does not reduce mortality or recurrence rate. However, these previous metaanalyses included a few RCTs that were small sample studies and appear to be of limited value in guiding clin- 
ical treatment. The recently published RCTs showed reduction in recurrent pulmonary embolism or death with thrombolysis compared with anticoagulant therapy. To investigate the benefits of thrombolysis in moderate pulmonary embolism, we performed an updated meta-analysis of RCTs comparing thrombolysis and anticoagulation in subjects with moderate pulmonary embolism.

\section{Methods}

\section{Study Identification}

We attempted to identify all relevant published RCTs comparing thrombolytic therapy and anticoagulant therapy for the initial treatment of moderate pulmonary embolism. We searched the MEDLINE and Embase databases from January 1980 to June 2013 and the Cochrane Library, Wanfang, and CNKI databases from January 1990 to June 2013 using the terms pulmonary embolism, thromboembolism, thrombolysis, fibrinolysis, recombinant tissue plasminogen activator, rt-PA, alteplase, randomized controlled trial, controlled clinical trial, and humans. We also searched references cited in journal articles.

\section{Study Selection}

Two investigators (Hong Chen MD and CR) independently evaluated studies for inclusion, and any disagreement was resolved by discussion. The criteria for inclusion were (1) proper randomization, (2) objectively diagnosed hemodynamically stable acute pulmonary embolism, (3) comparison of thrombolytic therapy and anticoagulant therapy for the initial treatment of pulmonary embolism, and (4) outcomes including death, pulmonary embolism recurrence, and bleeding. The criteria for exclusion were $(1)<18$ y of age, (2) pregnancy or lactation, and (3) objectively diagnosed massive acute pulmonary embolism.

\section{Data Extraction}

Two investigators (Hong Chen MD and CR) independently extracted data on the study design and quality and on the efficacy and safety outcomes during hospitalization or follow-up. In the event of discrepancy in the results obtained by the investigators concerning data extraction, the third investigator (Hong Chen MD PhD) helped in the final decision. Outcomes included (1) hemodynamically stable acute pulmonary embolism, (2) death, (3) pulmonary embolism recurrence, (4) major bleeding, (5) nonmajor bleeding, and (6) intracranial hemorrhage.

\section{Assessment of Study Quality}

We adopted the criteria for study quality outlined in the Cochrane Handbook for Systematic Reviews of Interven-

\section{QUICK LOOK}

\section{Current knowledge}

In patients with moderate pulmonary embolism, conflicting conclusions have been reached regarding the risk-benefit ratio of thrombolytic therapy to anticoagulant therapy in randomized trials and meta-analyses.

\section{What this paper contributes to our knowledge}

Compared with heparin, both mortality and pulmonary embolism recurrence are decreased by thrombolysis in patients with moderate pulmonary embolism. The risk of non-major bleeding increases, but the risk of major bleeding does not increase.

tions 5.1.0 (http://www.cochrane.org/handbook, accessed August 13, 2014) in the evaluation of studies included in the present meta-analysis. These criteria include (1) proper random sequence generation, (2) proper concealment of the allocation sequence, (3) blinding of the patient and the investigator assessing clinical outcomes to treatment allocation, and (4) completeness of follow-up. Two investigators (Hong Chen MD and CR) independently evaluated study quality, and any disagreements were resolved by discussion.

\section{Outcomes}

The primary efficacy outcome was a composite of recurrent pulmonary embolism or death. Secondary outcomes were the individual components of the primary outcome, and safety outcomes were major bleeding, non-major bleeding, and intracranial hemorrhage.

\section{Statistical Analysis}

We used a meta-analysis of all randomized trials comparing thrombolytic therapy and anticoagulant therapy in subjects with moderate pulmonary embolism by curative effect and safety index. Relative risks were combined using the Cochrane RevMan 5.2 software. We assessed the heterogeneity between studies with the Cochran Q test and took $P<.05$ as the threshold of statistical significance for heterogeneity and for calculating the effect of the odds ratio (OR) and 95\% CI. After clarifying the study effect of heterogeneity, we used a fixed-effects model based on the Mantel-Haenszel method ${ }^{5}$ for combining results from the individual trials. Potential publication bias was evaluated using the funnel plot approach.

\section{Results}

\section{Studies Included}

Figure 1 shows the study selection process. Sixteen RCTs comparing thrombolysis and anticoagulant therapy for sub- 


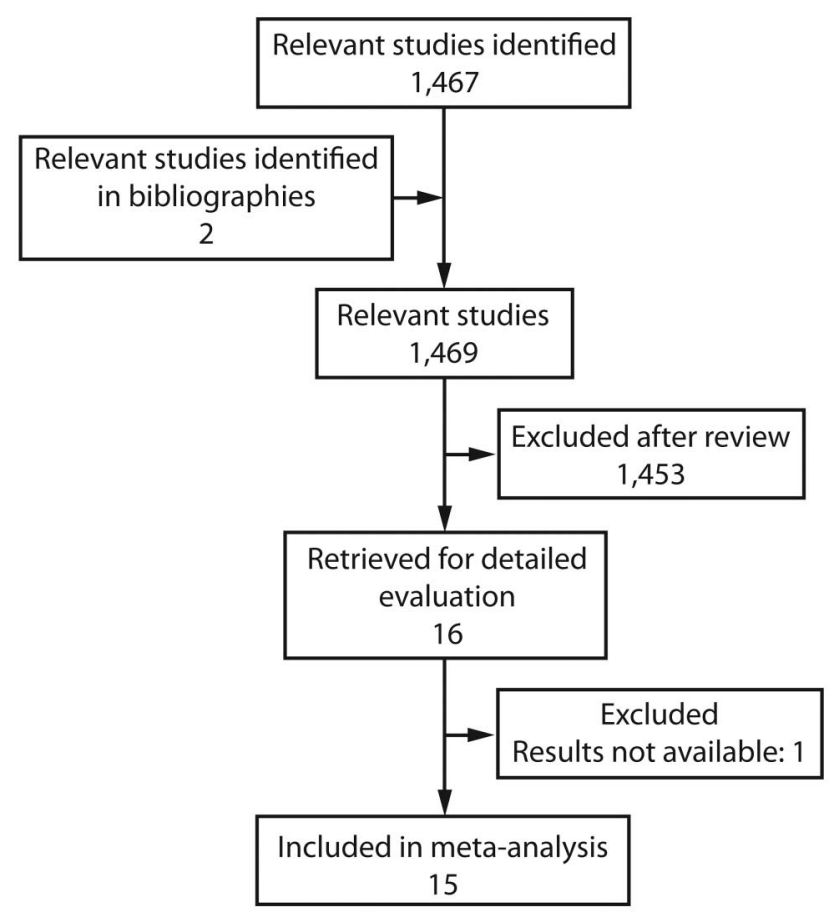

Fig. 1. Study flow chart.

jects with moderate pulmonary embolism were identified. Nine of the 16 trials were published in a foreign language and enrolled $\sim 1,708$ subjects $^{7-15}$ : one of them was excluded from this analysis because it was only a design and its results had not yet been published, ${ }^{15}$ and the other 8 trials involved 708 subjects (347 subjects treated with thrombolysis and 361 subjects treated with heparin). Seven of the 16 trials were Chinese documents involving 539 subjects with moderate pulmonary embolism ${ }^{16-22}: 270$ subjects treated with thrombolysis and 269 subjects treated with anticoagulant therapy. The designs of the studies included in the meta-analysis are summarized in Table 1.

\section{Study Quality}

Table 2 shows the methodological quality of randomized studies of thrombolysis for moderate pulmonary embolism. Randomized treatment allocation sequences were generated with random number tables or programs in 5 studies.11-14,20, Information about proper concealment of the treatment allocation was provided in one trial. ${ }^{10}$ Both subjects and investigators were blinded to treatment allocation in 5 trials. . $^{7,11-13}$ The number of subjects lost to follow-up was reported in 3 of the 15 trials. ${ }^{14,16,22}$

\section{Efficacy Outcomes}

Data on the primary outcome of recurrent pulmonary embolism or death are presented in Figure 2, and individual components of this outcome are presented in Table 3 .
Nine of the 15 studies showed a reduction in recurrent pulmonary embolism or death with thrombolysis compared with anticoagulant therapy. ${ }^{10,12-14,16,18-20,22}$ The pooled estimate from all of the trials revealed a statistically significant reduction in recurrent pulmonary embolism or death (1.94\% vs $5.87 \%$, OR $0.37,95 \%$ CI $0.21-0.66$ ), with no statistical evidence of heterogeneity among the studies $(P=.49)$. Similar estimates of treatment effect were obtained for death $(1.46 \%$ vs $3.81 \%$, OR $0.45,95 \%$ CI $0.23-$ $0.86)$ and recurrent pulmonary embolism $(0.81 \%$ vs $3.65 \%$, OR $0.32,95 \%$ CI $0.14-0.70$ ).

\section{Safety Outcomes}

Pooled data for safety outcomes are presented in Table 4. Eight of the 15 randomized trials suggested an increase in major bleeding for thrombolytic therapy compared with anticoagulant therapy. ${ }^{8-10,12,13,16,21,22}$ Nine of the randomized trials showed an increase in non-major bleeding with thrombolysis compared with heparin treatment. ${ }^{7,9,12,13,17,19-21,22}$ The pooled data revealed a nonstatistically significant increase in major bleeding $(3.57 \%$ vs $2.67 \%$, OR $1.34,95 \%$ CI $0.70-2.58$ ) but a statistically significant increase in non-major bleeding $(12.78 \%$ vs $3.65 \%$, OR $4.12,95 \%$ CI 2.37-7.17).

\section{Subgroup Analyses}

Table 5 provides a subgroup analysis comparing foreign and Chinese subjects. Compared with heparin treatment, thrombolytic therapy was associated with a significant reduction in recurrent pulmonary embolism or death in the 8 studies with 708 foreign subjects with moderate pulmonary embolism ( $3.46 \%$ vs $7.76 \%$, OR $0.45,95 \%$ CI 0.23 0.86 ) and in the 7 trials with 539 Chinese subjects ( $0 \%$ vs $3.72 \%$, OR $0.18,95 \%$ CI $0.05-0.73)$, with no statistical evidence of heterogeneity $(P=.12)$. Similar estimates of treatment safety were obtained for major bleeding in foreign subjects $(3.46 \%$ vs $2.77 \%$, OR $1.19,95 \%$ CI $0.51-$ 2.79) and Chinese subjects (3.70\% vs $2.23 \%$, OR 1.59 , 95\% CI 0.57-4.45), with no statistical evidence of heterogeneity $(P=.67)$.

\section{Sensitive Analyses}

Deletion of individual trials did not significantly change the primary outcome. Because this meta-analysis included randomized trials with small samples, most of scatter distributed at the bottom of the funnel plot (Fig. 3). The funnel plot of effect size versus study precision was comparatively symmetrical, with a similar number of studies on either side of the summary treatment effect for recurrent pulmonary embolism or death. This is consistent with a lack of major publication bias. 


\section{Thrombolysis vs Anticoagulation for Treatment of Moderate Pulmonary Embolism}

Table 1. Design of Studies Included in the Meta-Analysis

\begin{tabular}{|c|c|c|c|c|c|c|}
\hline Reference & PE Severity & Eligibility & Treatment & $n$ & PE Assessment & Follow-up \\
\hline \multirow[t]{2}{*}{ Levine et $\mathrm{al}^{7}$} & \multirow[t]{2}{*}{ Moderate } & \multirow[t]{2}{*}{ Acute $\mathrm{PE}$ symptoms $\leq 14 \mathrm{~d}$} & rt-PA, 2 min & 33 & \multirow[t]{2}{*}{ AGF, LS } & \multirow[t]{2}{*}{$10 \mathrm{~d}$} \\
\hline & & & Heparin & 25 & & \\
\hline \multirow[t]{2}{*}{ PIOPED $^{8}$} & \multirow[t]{2}{*}{ Moderate } & \multirow[t]{2}{*}{ Acute PE symptoms $\leq 7 \mathrm{~d}$} & rt-PA, $40-90 \mathrm{~min}$ & 9 & \multirow[t]{2}{*}{ AGF, LS } & \multirow[t]{2}{*}{$7 \mathrm{~d}$} \\
\hline & & & Heparin & 4 & & \\
\hline \multirow[t]{2}{*}{ PAIMS ${ }^{9}$} & \multirow[t]{2}{*}{ Moderate } & \multirow[t]{2}{*}{ Acute PE symptoms $\leq 10 \mathrm{~d}$} & rt-PA, 2 h & 20 & \multirow[t]{2}{*}{ AGF } & \multirow[t]{2}{*}{$30 \mathrm{~d}$} \\
\hline & & & Heparin & 16 & & \\
\hline \multirow[t]{2}{*}{ Goldhaber et al ${ }^{10}$} & \multirow[t]{2}{*}{ Moderate } & \multirow[t]{2}{*}{ Acute $\mathrm{PE}$ symptoms $\leq 14 \mathrm{~d}$} & rt-PA, 2 h & 46 & \multirow[t]{2}{*}{ AGF, LS } & \multirow{2}{*}{$\begin{array}{c}\text { In-hospital } \\
\text { or } 14 \mathrm{~d}\end{array}$} \\
\hline & & & Heparin & 55 & & \\
\hline \multirow[t]{2}{*}{ Konstantinides et $\mathrm{al}^{11}$} & \multirow[t]{2}{*}{ Moderate } & \multirow[t]{2}{*}{ Acute PE symptoms $\leq 4 \mathrm{~d}$} & rt-PA, 2 h & 118 & \multirow[t]{2}{*}{ AGF, LS, spiral CT } & \multirow[t]{2}{*}{$\begin{array}{l}\text { In-hospital } \\
\text { or } 30 \mathrm{~d}\end{array}$} \\
\hline & & & Heparin & 138 & & \\
\hline \multirow[t]{2}{*}{ Lu et al ${ }^{16}$} & \multirow[t]{2}{*}{ Moderate } & \multirow[t]{2}{*}{ Acute PE symptoms $\leq 14 \mathrm{~d}$} & Urokinase, $2 \mathrm{~h}$ & 51 & \multirow[t]{2}{*}{$\begin{array}{l}\text { CT pulmonary } \\
\text { angiography }\end{array}$} & \multirow[t]{2}{*}{$12 \mathrm{mo}$} \\
\hline & & & Heparin & 55 & & \\
\hline Becattini et al ${ }^{12}$ & Moderate & Acute PE symptoms $\leq 10 \mathrm{~d}$ & $\begin{array}{l}\text { Tenecteplase bolus, } \\
6 \mathrm{~h}\end{array}$ & 23 & AGF, LS, spiral CT & $7 \mathrm{~d}$ \\
\hline & & & Heparin & 28 & & \\
\hline Fasullo et al ${ }^{13}$ & Moderate & Acute PE symptoms $\leq 6 \mathrm{~h}$ & Alteplase, $2 \mathrm{~h}$ & 37 & Spiral CT & $6 \mathrm{mo}$ \\
\hline & & & Heparin & 35 & & \\
\hline Wei and Sun ${ }^{17}$ & Moderate & Acute PE symptoms $\leq 14 \mathrm{~d}$ & rt-PA, 2 h & 28 & $\begin{array}{l}\mathrm{CT} \text { pulmonary } \\
\text { angiography }\end{array}$ & $14 \mathrm{~d}$ \\
\hline & & & Heparin & 26 & & \\
\hline $\mathrm{Ou}^{18}$ & Moderate & Acute PE symptoms $\leq 14 \mathrm{~d}$ & Urokinase, $2 \mathrm{~h}$ & 54 & $\begin{array}{l}\text { CT pulmonary } \\
\text { angiography }\end{array}$ & $7 \mathrm{~d}$ \\
\hline & & & Heparin & 54 & & \\
\hline $\operatorname{Sun}^{19}$ & Moderate & Acute PE symptoms & Urokinase, $2 \mathrm{~h}, 2 \mathrm{~d}$ & 46 & $\begin{array}{r}\text { CT pulmonary } \\
\text { angiography }\end{array}$ & $30 \mathrm{~d}$ \\
\hline & & & Heparin & 46 & & \\
\hline $\mathrm{Wu}$ et $\mathrm{a}^{20}$ & Moderate & Acute PE symptoms & Urokinase, $2 \mathrm{~h}$ & 35 & $\begin{array}{r}\text { CT pulmonary } \\
\text { angiography }\end{array}$ & $>6 \mathrm{mo}$ \\
\hline & & & Heparin & 35 & & \\
\hline Zhang et $\mathrm{a}^{21}$ & Moderate & Acute PE symptoms $\leq 14 \mathrm{~d}$ & rt-PA, 2 h & 26 & $\begin{array}{l}\mathrm{CT} \text { pulmonary } \\
\text { angiography }\end{array}$ & $14 \mathrm{~d}$ \\
\hline & & & Heparin & 29 & & \\
\hline MOPETT $^{14}$ & Moderate & Acute PE symptoms $\leq 10 \mathrm{~d}$ & $\begin{array}{l}\text { Weight } \geq 50 \mathrm{~kg}, \\
50 \mathrm{mg} \mathrm{rt}-\mathrm{PA} \\
\text { Weight } \leq 50 \mathrm{~kg}, \\
0.5 \mathrm{mg} \text { rt-PA } / \mathrm{kg}\end{array}$ & 61 & $\begin{array}{l}\text { CT pulmonary } \\
\text { angiography }\end{array}$ & $28 \mathrm{mo}$ \\
\hline & & & Heparin & 60 & & \\
\hline Liu et $\mathrm{al}^{22}$ & Moderate & Acute PE symptoms & rt-PA, 2 h & 30 & $\begin{array}{l}\text { CT pulmonary } \\
\text { angiography }\end{array}$ & $6 \mathrm{mo}$ \\
\hline & & & Heparin & 24 & & \\
\hline $\begin{array}{l}\mathrm{PE}=\text { pulmonary embolism } \\
\text { PIOPED = Prospective Inves } \\
\text { PAIMS = Plasminogen Activ } \\
\text { MOPETT = Moderate Pulmo } \\
\text { rt-PA = recombinant tissue-ty } \\
\text { AGF = angiography } \\
\text { LS = lung scan } \\
\text { CT = computed tomography }\end{array}$ & $\begin{array}{l}\text { on of Pulmonary } \\
\text { talian Multicenter } \\
\text { Embolism Treated } \\
\text { asminogen activat }\end{array}$ & $\begin{array}{l}\text { ism Diagnosis } \\
\text { Thrombolysis }\end{array}$ & & & & \\
\hline
\end{tabular}

\section{Discussion}

This meta-analysis of currently available RCTs showed some statistically significant benefits from thrombolytic therapy compared with anticoagulant therapy for the initial treatment of patients with moderate pulmonary embolism. Thrombolysis can reduce mortality or recurrence rate in patients with moderate pulmo- 
Table 2. Methodological Quality of Randomized Studies of Thrombolysis in Pulmonary Embolism

\begin{tabular}{|c|c|c|c|c|c|}
\hline Reference & $\begin{array}{l}\text { Random Sequence } \\
\text { Generation }\end{array}$ & $\begin{array}{c}\text { Allocation } \\
\text { Concealment }\end{array}$ & Double-Blind & $\begin{array}{l}\text { Loss to } \\
\text { Follow-Up }\end{array}$ & $\begin{array}{l}\text { Baseline } \\
\text { Differences }\end{array}$ \\
\hline Levine et $\mathrm{al}^{7}$ & Unclear & Not stated & Yes & No & No \\
\hline PIOPED $^{8}$ & Unclear & Not stated & Yes & No & No \\
\hline PAIMS $^{9}$ & Unclear & Not stated & No & Not stated & Yes \\
\hline Goldhaber et al ${ }^{10}$ & Unclear & Yes & No & No & No \\
\hline Konstantinides et al ${ }^{11}$ & Clear & Not stated & Yes & Not stated & No \\
\hline Lu et $\mathrm{al}^{16}$ & Unclear & Not stated & No & Yes & No \\
\hline Becattini et al ${ }^{12}$ & Clear & Not stated & Yes & Not stated & No \\
\hline Fasullo et al ${ }^{13}$ & Clear & Not stated & Yes & Not stated & No \\
\hline Wei and Sun, ${ }^{17}$ & Unclear & Not stated & No & No & No \\
\hline $\mathrm{Ou}^{18}$ & Unclear & Not stated & No & No & No \\
\hline Sun $^{19}$ & Unclear & Not stated & No & No & No \\
\hline $\mathrm{Wu}$ et $\mathrm{al}^{20}$ & Clear & Not stated & No & Not stated & No \\
\hline Zhang et $\mathrm{al}^{21}$ & Unclear & Not stated & No & No & No \\
\hline MOPETT $^{14}$ & Clear & Not stated & No & Yes & No \\
\hline Liu et $\mathrm{al}^{22}$ & Unclear & Not stated & No & Yes & No \\
\hline \multicolumn{6}{|c|}{$\begin{array}{l}\text { PIOPED }=\text { Prospective Investigation of Pulmonary Embolism Diagnosis } \\
\text { PAIMS }=\text { Plasminogen Activator Italian Multicenter Study } \\
\text { MOPETT = Moderate Pulmonary Embolism Treated with Thrombolysis }\end{array}$} \\
\hline
\end{tabular}

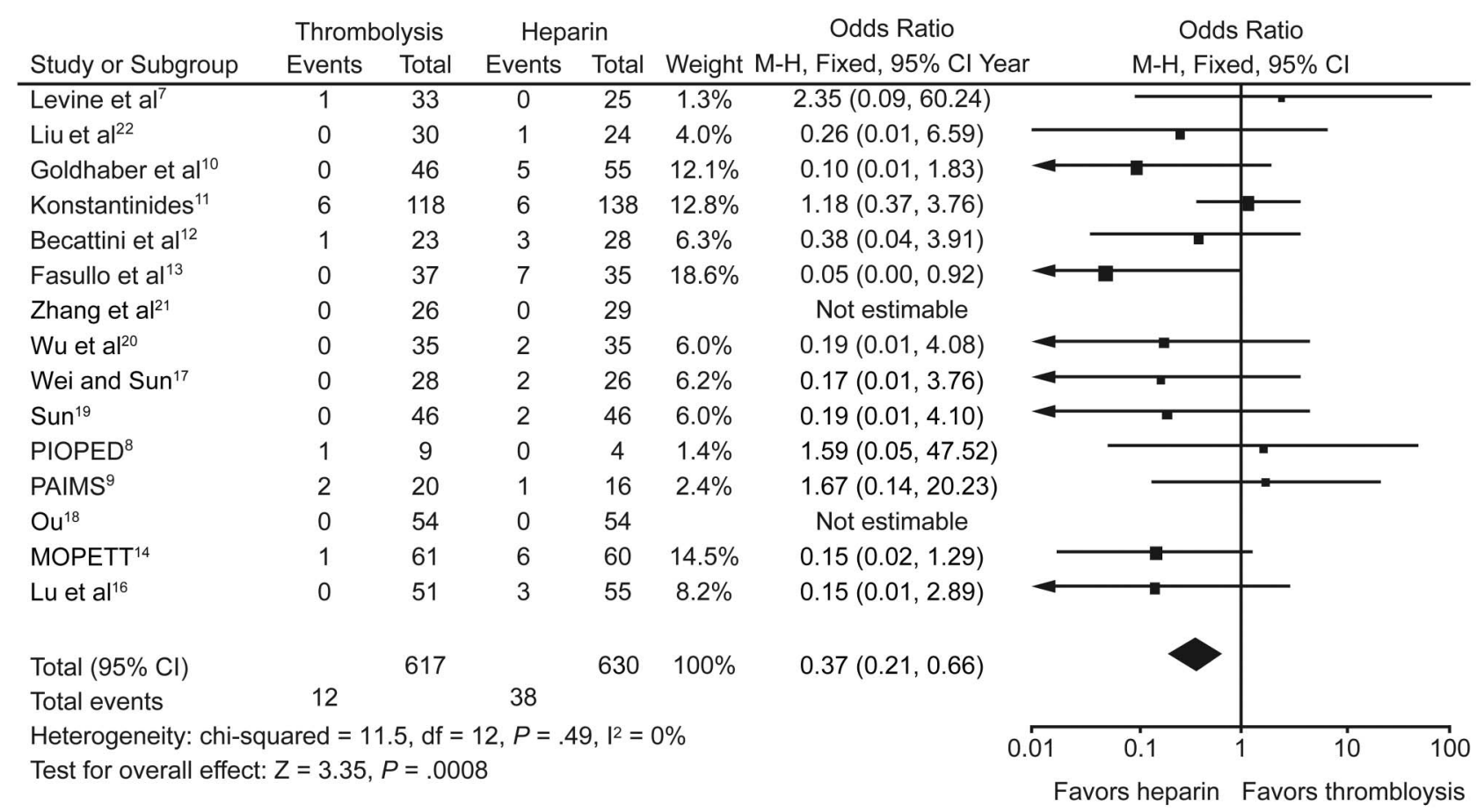

Fig. 2. The primary outcome of recurrent pulmonary embolism or death for thrombolysis versus anticoagulant therapy for the initial treatment of moderate pulmonary embolism. PIOPED = Prospective Investigation of Pulmonary Embolism Diagnosis; PAIMS = Plasminogen Activator Italian Multicenter Study; MOPETT = Moderate Pulmonary Embolism Treated with Thrombolysis.

nary embolism. Compared with anticoagulation, thrombolytic therapy was associated with a significant reduction in recurrent pulmonary embolism or death in trials that also enrolled both foreign subjects with moderate pulmonary embolism and Chinese subjects. Nine studies ${ }^{10,12-14,16,18-20,22}$ showed a lower mortality or recurrence rate with thrombolysis compared with anticoagulation for the initial treatment of moderate pulmonary embolism. Compared with anticoagulation, thrombolytic therapy was associated with a significant 
Table 3. Data on Primary Outcome of Recurrent Pulmonary Embolism or Death

\begin{tabular}{lcccc}
\hline \hline \multicolumn{1}{c}{ Outcome } & $\begin{array}{c}\text { Thrombolysis, } \\
n / N(\%)\end{array}$ & $\begin{array}{c}\text { Heparin, } \\
n / N(\%)\end{array}$ & OR (95\% CI) & $\begin{array}{c}P \\
(\text { Heterogeneity) }\end{array}$ \\
\hline Recurrent pulmonary embolism or death & $12 / 617(1.94)$ & $37 / 630(5.87)$ & $0.37(0.21-0.66)$ \\
Death & $9 / 617(1.46)$ & $24 / 630(3.81)$ & $0.45(0.23-0.86)$ & .49 \\
Recurrent pulmonary embolism & $5 / 617(0.81)$ & $23 / 630(3.65)$ & $0.32(0.14-0.70)$ & .75 \\
OR = odds ratio. & & & & \\
\hline
\end{tabular}

Table 4. Pooled Data for Safety Outcomes of Thrombolysis Versus Heparin Treatment

\begin{tabular}{lllll}
\hline \hline \multicolumn{1}{c}{ Outcome } & $\begin{array}{c}\text { Thrombolysis, } \\
n / N(\%)\end{array}$ & $\begin{array}{c}\text { Heparin, } \\
n / N(\%)\end{array}$ & OR (95\% CI) & $\begin{array}{c}P \\
(\text { Heterogeneity) }\end{array}$ \\
\hline Major bleeding & $22 / 617(3.57)$ & $16 / 630(2.67)$ & $1.34(0.70-2.58)$ & .85 \\
Non-major bleeding & $69 / 540(12.78)$ & $20 / 548(3.65)$ & $4.12(2.37-7.17)$ & .37 \\
Bleeding & $70 / 564(12.41)$ & $35 / 578(6.06)$ & $2.14(1.36-3.36)$ & .21 \\
\hline
\end{tabular}

Table 5. Subgroup Analysis of Foreign and Chinese Subjects

\begin{tabular}{|c|c|c|c|c|c|c|c|}
\hline \multirow{2}{*}{ Outcome } & \multicolumn{3}{|c|}{ Foreign Subjects } & \multicolumn{3}{|c|}{ Chinese Subjects } & \multirow{2}{*}{$\begin{array}{c}P \\
\text { (Heterogeneity) }\end{array}$} \\
\hline & $\begin{array}{c}\text { Thrombolysis, } \\
n / N(\%)\end{array}$ & $\begin{array}{l}\text { Heparin, } \\
n / N(\%)\end{array}$ & OR $(95 \% \mathrm{CI})$ & $\begin{array}{l}\text { Thrombolysis, } \\
n / N(\%)\end{array}$ & $\begin{array}{l}\text { Heparin, } \\
n / N(\%)\end{array}$ & OR $(95 \% \mathrm{CI})$ & \\
\hline $\begin{array}{l}\text { Recurrent pulmonary } \\
\text { embolism or death }\end{array}$ & $12 / 347(3.46)$ & 28/361 (7.76) & $0.45(0.23-0.86)$ & $0 / 270(0.00)$ & $10 / 269(3.72)$ & $0.18(0.05-0.73)$ & .12 \\
\hline Death & $9 / 347(2.59)$ & $16 / 361(4.43)$ & $0.58(0.27-1.24)$ & $0 / 270(0.00)$ & $8 / 269$ (2.97) & $0.22(0.05-0.88)$ & .11 \\
\hline $\begin{array}{l}\text { Recurrent pulmonary } \\
\text { embolism }\end{array}$ & $5 / 347(1.44)$ & $19 / 361(5.26)$ & $0.35(0.15-0.82)$ & $0 / 270(0.00)$ & 4/269 (1.49) & $0.19(0.02-1.66)$ & .57 \\
\hline Major bleeding & $12 / 347(3.46)$ & $10 / 361$ (2.77) & $1.19(0.51-2.79)$ & $10 / 270(3.70)$ & $6 / 269(2.23)$ & $1.59(0.57-4.45)$ & .67 \\
\hline
\end{tabular}

increase in non-major bleeding but a nonsignificant increase in major bleeding.

Compared with previous meta-analyses, this study has provided conflicting conclusions about the benefits of thrombolysis in patients with moderate pulmonary embolism. A recent meta-analysis, ${ }^{6}$ which included only 5 randomized trials ${ }^{7-11}$ and involved 464 subjects, reported no significantly decreased mortality or recurrent pulmonary embolism, whereas we showed a significant benefit of thrombolysis compared with anticoagulation for the initial treatment of moderate pulmonary embolism. Our study included 15 trials involving 1,247 subjects and could lead to more valid results for the initial treatment of moderate pulmonary embolism. The subgroup analysis, which included 8 foreign studies involving 708 subjects, also showed that thrombolysis resulted in a significant reduction in pulmonary embolism recurrence or death compared with heparin treatment. The Pulmonary Embolism Thrombolysis (PEITHO) trial ${ }^{15}$ is a prospective, multi-center, international, randomized, double-blind comparison of tenecteplase versus placebo in subjects with moderate pulmonary embolism and is expected to enroll $\sim 1,000$ sub-

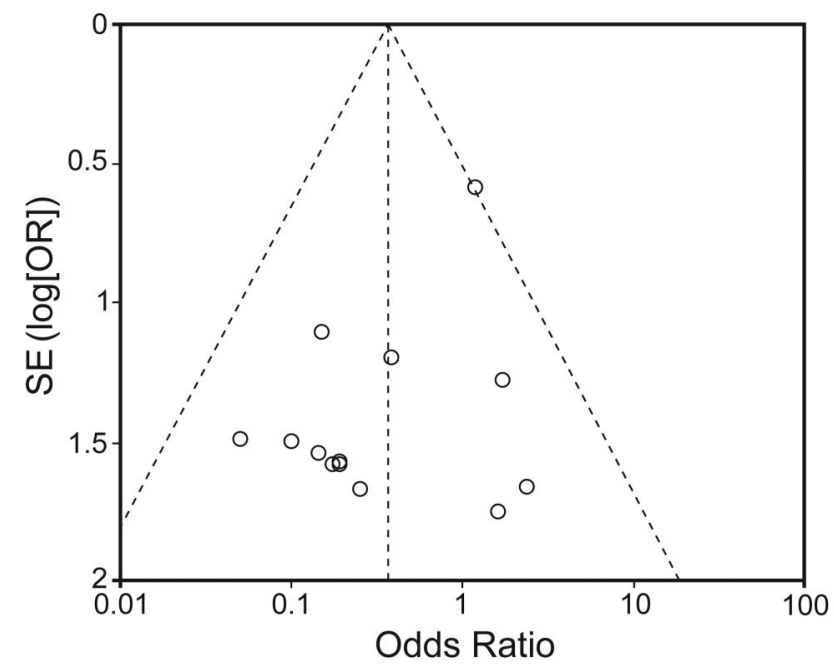

Fig. 3. Funnel plot of effect size versus study precision of recurrent pulmonary embolism or death. $\mathrm{OR}=$ odds ratio.

jects, to determine the benefits versus risks of thrombolysis in moderate pulmonary embolism, and to answer a query on the management of this patient population; the 


\section{Thrombolysis vs Anticoagulation for Treatment of Moderate Pulmonary Embolism}

authenticity of the result of this meta-analysis can be further defined. Geibel et al ${ }^{23}$ pointed out that women with submassive pulmonary embolism might benefit less from thrombolytic treatment in terms of survival and pulmonary embolism recurrence and that they could be exposed to a higher bleeding risk compared with men. Compared with previous meta-analyses, this meta-analysis included more randomized trials, and the number of men compared with women in the Chinese studies included was larger. Perhaps the greater reduction in mortality and pulmonary embolism recurrence with thrombolysis was due to the larger number of male subjects. However, the ratio of male to female subjects in the foreign studies was close to $1: 1$, which supports the conclusion of this meta-analysis that thrombolytic therapy can reduce mortality and pulmonary embolism recurrence rate. Because the study by Geibel et $\mathrm{al}^{23}$ is not an RCT, it is necessary to use large RCTs to determine whether there are differences between males and females regarding the benefits and risks of thrombolytic therapy for moderate pulmonary embolism.

We conclude that thrombolysis can improve clinical outcome and is worth putting into clinical practice. Because the total hemorrhage rate of thrombolysis was 2 times that of anticoagulant therapy in subjects with moderate pulmonary embolism, the clinical application of thrombolytic therapy is still limited. Based on the conditions and weights of patients, reducing the dose of thrombolytic drugs can decrease the risk of major bleeding ${ }^{8,14}$; thus, we look forward to more clinical studies to determine the safe dose of thrombolysis for moderate pulmonary embolism. Of course, because of deterioration during anticoagulant therapy, upgraded treatment such as thrombolysis was selected, which can improve symptoms quickly, reduce pulmonary artery pressure, and improve right ventricle dysfunction. ${ }^{11,17}$ In addition, thrombolysis does cause a decline in the eventfree survival rate after a 1-y follow-up compared with anticoagulation. ${ }^{16}$ The efficacy of thrombolysis could be confirmed by expanding the limited follow-up time.

This study has several potential limitations. First, in every study included, the number of subjects and the number of outcome events are low, so this meta-analysis has a limited statistical power. However, compared with previous meta-analyses, ours included more studies. Second, our meta-analysis included 7 Chinese studies. Although they clarified the consistent research group and control group at baseline, most of the literature did not show random distribution. Due to ethnic differences, we performed a subgroup analysis of foreign and Chinese subjects. Finally, the trials did not limit follow-up time. However, this does not preclude pooling of the results because it is only within the same studies that subjects are directly compared with each other. Because the trials that were included in this meta-analysis did not limit the type or dosage of thrombolytic drugs, this may be the major bias in this analysis.
However, one previous meta-analysis ${ }^{24}$ concluded that different thrombolytic drugs share similar efficacy and safety.

\section{Conclusions}

Both mortality and pulmonary embolism recurrence are decreased by thrombolysis compared with heparin treatment in patients with moderate pulmonary embolism. Thrombolysis is worth putting into clinical practice. However, this study and the previous meta-analyses have reached conflicting conclusions regarding the efficacy of thrombolysis. Compared with heparin treatment, thrombolytic therapy increases the risk of non-major bleeding, but not major bleeding. Further evaluation of the efficacy and safety of thrombolysis for the treatment of moderate pulmonary embolism appears to be warranted.

\section{ACKNOWLEDGEMENTS}

We thank Zhenguo Zhai MD PhD for editing.

\section{REFERENCES}

1. Aujesky D, Jimenez D, Mor MK, Geng M, Fine MJ, Ibrahim SA. Weekend versus weekday admission and mortality after acute pulmonary embolism. Circulation 2009;119(7):962-968.

2. Laporte S, Mismetti P, Décousus H, Uresandi F, Otero R, Lobo JL, et al. Clinical predictors for fatal pulmonary embolism in 15,520 patients with venous thromboembolism: findings from the Registro Informatizado de la Enfermedad TromboEmbolica venosa (RIETE) Registry. Circulation 2008;117(13):1711-1716.

3. Ramakrishnan N. Thrombolysis is not warranted in submassive pulmonary embolism: a systematic review and meta-analysis. Crit Care Resusc 2007;9(4):357-363.

4. Worster A, Smith C, Silver S, Brown MD. Evidence-based emergency medicine/critically appraised topic. Thrombolytic therapy for submassive pulmonary embolism? Ann Emerg Med 2007;50(1):7884.

5. Wan S, Quinlan DJ, Agnelli G, Eikelboom JW. Thrombolysis compared with heparin for the initial treatment of pulmonary embolism: a meta-analysis of the randomized controlled trials. Circulation 2004 . 110(6):744-749.

6. Tardy B, Venet C, Zeni F, Coudrot M, Guyomarc'h S, Mismetti P. Short term effect of recombinant tissue plasminogen activator in patients with hemodynamically stable acute pulmonary embolism: results of a meta-analysis involving 464 patients. Thromb Res 2009; 124(6):672-677.

7. Levine M, Hirsh J, Weitz J, Cruickshank M, Neemeh J, Turpie AG, Gent M. A randomized trial of a single bolus dosage regimen of recombinant tissue plasminogen activator in patients with pulmonary embolism. Chest 1990;98(6):1473-1479.

8. PIOPED Investigators. Tissue plasminogen activator for the treatment of acute pulmonary embolism: a collaborative study. Chest 1990;97(3):528-533

9. Dalla-Volta S, Palla A, Santolicandro A, Giuntini C, Pengo V, Visioli $\mathrm{O}$, et al. PAIMS 2: alteplase combined with heparin versus heparin in the treatment of acute pulmonary embolism. Plasminogen Activator Italian Multicenter Study 2. J Am Coll Cardiol 1992;20(3): 520-526.

10. Goldhaber SZ, Haire WD, Feldstein ML, Miller M, Toltzis R, Smith $\mathrm{JL}$, et al. Alteplase versus heparin in acute pulmonary embolism: 


\section{Thrombolysis vs Anticoagulation for Treatment of Moderate Pulmonary Embolism}

randomized trial assessing right ventricular function and pulmonary perfusion. Lancet 1993;341(8844):507-511.

11. Konstantinides S, Geibel A, Heusel G, Heinrich F, Kasper W, Management Strategies and Prognosis of Pulmonary Embolism-3 Trial Investigators. Heparin plus alteplase compared with heparin alone in patients with submassive pulmonary embolism. N Engl J Med 2002; 347(15):1143-1150.

12. Becattini C, Agnelli G, Salvi A, Grifoni S, Pancaldi LG, Enea I, et al. Bolus tenecteplase for right ventricle dysfunction in hemodynamically stable patients with pulmonary embolism. Thromb Res 2010; 125(3):e82-e86.

13. Fasullo S, Scalzo S, Maringhini G, Ganci F, Cannizzaro S, Basile I, et al. Six-month echocardiographic study in patients with submassive pulmonary embolism and right ventricle dysfunction: comparison of thrombolysis with heparin. Am J Med Sci 2011;341(1):33-39.

14. Sharifi M, Bay C, Skrocki L, Rahimi F, Mehdipour M, "MOPETT" Investigators. Moderate pulmonary embolism treated with thrombolysis (from the "MOPETT" Trial). Am J Cardiol 2013;111(2):273-277.

15. Steering Committee. Single-bolus tenecteplase plus heparin compared with heparin alone for normotensive patients with acute pulmonary embolism who have evidence of right ventricular dysfunction and myocardial injury: rationale and design of the Pulmonary Embolism Thrombolysis (PEITHO) trial. Am Heart J 2012;163(1): 33.e1-38.e1.

16. Lu WH, Tang ZZ, Ma Y, Yu ZH. Long term prognosis of thrombolytic therapy with urokinase and/or anticoagulant in submassive pulmonary embolism. Clin J Med Offic 2008;36(3):340-342.
17. Wei L, Sun FC. Curative effect of thrombolysis and anticoagulant therapy on submassive pulmonary embolism patients. Int J Respir 2012;32(19):1471-1473.

18. Ou YQ. Analysis of therapeutic effect of urokinase combined with sequential anti-coagulation in submassive pulmonary embolism. J Hainan Med Univ 2012;18(7):897-898.

19. Sun RQ. Curative effect of urokinase combined with low-molecularweight heparin, warfarin in submassive pulmonary embolism. Strait Pharm J 2012;24(5):130-131.

20. Wu TX, Lin GS, Chen GH, Chen LQ. Curative effect of thrombolysis combined with sequential anti-coagulation in submassive pulmonary embolism. J Clin Intern Med 2012;28(12):835-836.

21. Zhang XL, Jiang SH, Jiang LN, Shan FL, Li Z, Qin MH. Clinical observation of small doses of rt-PA thrombolysis for 26 cases of elderly patients with acute submassive pulmonary embolism. Shandong Med J 2012;52(3):69-70.

22. Liu LH, Lu SJ, Liu Z. Curative effect of thrombolysis and anticoagulant therapy for patients with submassive pulmonary embolism. Chongqing Med 2013;42(11):1288-1290.

23. Geibel A, Olschewski M, Zehender M, Wilsch M, Odening K, Heinrich F, et al. Possible gender-related differences in the risk-tobenefit ratio of thrombolysis for acute submassive pulmonary embolism. Am J Cardiol 2007;99(1):103-107.

24. Qin ZQ, Wang C. Comparison of different thrombolytics in treatment of pulmonary thromboembolism: a meta-analysis. Sect Respir Sys Foreign Med Sci 2005;25(1):1-4. 